\title{
Species composition, blood meal hosts and Plasmodium infection rates of Anopheles mosquitoes in Ghibe River Basin, southwestern Ethiopia
}

Dejene Getachew ${ }^{1,2^{*}}$, Teshome Gebre-Michael ${ }^{3 \wedge}$, Meshesha Balkew ${ }^{4}$ and Habte Tekie ${ }^{2}$

\begin{abstract}
Background: Vector control interventions using long-lasting insecticidal nets (LLINS) and indoor residual spraying (IRS) are commonly practiced tools for the control of malaria in Ethiopia. In order to evaluate the effectiveness of these control interventions, and understand the prevailing malaria vectors, their incrimination in disease transmission, and their resting and feeding behavior, we set out to identify the Anopheles species, their blood meal sources, and entomological inoculation rate (EIR) in Ghibe and Darge within the Ghibe River basin, southwestern Ethiopia.

Methods: Adult Anopheles mosquitoes were sampled both indoors and outdoors from January 2015 to October 2016 using Centers for Disease Control and Prevention (CDC) light traps, pyrethrum spray catch (PSC), artificial pit shelters and mouth aspirators. Mosquito species were morphologically identified, and their blood meal sources and malaria sporozoite rates were assessed using enzyme-linked immunosorbent assays.

Results: In total, 13 species of Anopheles mosquitoes were identified, among which Anopheles gambiae (s.l.) was the predominant species: 87.9 and $67.7 \%$ in Ghibe and Darge, respectively. The mean density of An. gambiae (s.l.) collected per night using CDC light traps was 1.8 and 0.7 outdoors and indoors, respectively, in Ghibe, and 0.125 and 0.07 indoors and outdoors, respectively, in Darge. Anopheles mosquito abundance was higher in houses near the river than in houses far from the river in both study sites. Among Anopheles mosquitoes sampled using CDC light trap catches, $67.6 \%$ were unfed and the indoor and outdoor human blood indices of An. gambiae (s.l.) were 58.4 and 15.8\%, respectively in Ghibe, while in Darge, they were 57.1 and $50 \%$, respectively. Sporozoite rates were $0.07 \%$ for $P$. vivax and $0.07 \%$ for P. falciparum in Ghibe and zero in Darge. In Ghibe, the overall EIRs for P. falciparum and P. vivax were zero and 8.4 infective bites/person/year, respectively, in 2015, while zero and 5.4 infective bites/person/year for $P$. vivax and $P$. falciparum, respectively, in 2016. No Plasmodium-positive Anopheles mosquitoes were identified from Darge.
\end{abstract}

Conclusions: Anopheles gambiae (s.l.), the principal vector of malaria in Ethiopia was the most abundant species both indoors and outdoors, fed both on human and cattle blood and occurred at higher frequencies near rivers. Anopheles gambiae (s.l.) that were circumsporozoite-positive for Plasmodium species were collected from Ghibe, but not Darge.

Keywords: Anopheles gambiae (s.l.), Bovine blood index, Darge, Ghibe, Human blood index

\footnotetext{
*Correspondence: dejenegbt@gmail.com

^Teshome Gebre-Michael-Deceased

1 Department of Biology, Dire Dawa University, P. O. Box 1362, Dire Dawa,

Ethiopia

Full list of author information is available at the end of the article
} 


\section{Background}

Malaria has an overwhelming impact on people's health and livelihoods with an estimated 216 million cases and 445,000 deaths globally in 2016 and about $91 \%$ of all malaria deaths being in Africa [1]. In Ethiopia, malaria is a major public health problem with variable transmission and occurrence. Malaria transmission is seasonal and shows variation in its endemicity in the country due to its large diversity in altitude, rainfall, and population movement [2].

In Ethiopia, approximately $68 \%$ of the population lives in malaria endemic regions. It has been estimated that 2.8 million cases and 4900 deaths occurred because of malaria in 2015. In Ethiopia, Plasmodium falciparum accounts for $64 \%$ of the malaria cases while Plasmodium vivax accounts for $36 \%[2,3]$, but these percentages might not be constant because of the high degree of seasonal variation in Plasmodium species [4-7]. Lowland areas are endemic to malaria while highlands and highland fringe areas are prone to epidemics associated with unusually high minimum temperature together with a lack of immunity in populations [8]. Reports have shown that the number of malaria cases and deaths declined after the scale-up of deployment of artemisinin-based combination therapy (ACT), IRS and wide distribution of LLINs $[9,10]$.

Anopheles arabiensis, a member of An. gambiae (s.l.), is the principal malaria vector in Ethiopia, whereas Anopheles pharoensis, Anopheles funestus, and Anopheles nili are considered secondary vectors $[3,11]$. Understanding the biting and resting habits of Anopheles mosquitoes is essential for the implementation of effective vector control interventions [12].

In Ethiopia, malaria vector control relies heavily on IRS and the distribution of LLINs [2]. Indoor residual spraying and LLINs are intradomiciliary-based control measures effective for vectors that closely depend on humans for feeding and resting inside houses [13]. The presence of outdoor feeding and resting Anopheles mosquitoes, which cannot be targeted with IRS and LLINs, has resulted in failure of malaria elimination [13]. The presence of these insecticide-based interventions may lead to shifts in the biting behavior of the vectors from indoor to outdoor, from human to animal, and from early before bed time or late at night (dawn) [13-16].

Factors such as the expansion of irrigation schemes $[17,18]$, construction of large dams [19], asymptomatic subpatent Plasmodium carriage in low endemic or preelimination transmission settings [20], vector resistance to insecticides [21-23] and drug resistance [24, 25] might pose problems in control and eventual elimination of malaria in Ethiopia. To achieve malaria elimination, both escalation of the current control methods and development of novel interventions to interrupt transmission are needed. Planning and implementation of vector interventions require an understanding of the biology of the important malaria vectors [26].

Thus far, no studies have been conducted on Anopheles mosquito species composition, resting behavior, blood meal sources and their disease transmission potential in the study area. An understanding of the local malaria vector species, resting sites, blood meal sources, and their disease incrimination is extremely vital for malaria control and its elimination. Hence, the objective of this study was to identify the Anopheles mosquito species, their resting behavior, blood meal sources and the EIR in the Ghibe River basin, southwestern Ethiopia.

\section{Methods}

\section{Study area}

The study was conducted in Ghibe and Darge study sites located within the Ghibe River Basin, in southwestern Ethiopia in Abeshge district, Guraghe Zone, Southern Nations Nationalities and Peoples Regional State (Fig. 1). The zonal and Abeshge district town (Wolkite) is located $158 \mathrm{~km}$ southwest of Addis Ababa. Based on information obtained from the district health office, the area is endemic to malaria. In each study site, there are perennial rivers. Ghibe $\left[8^{\circ} 14^{\prime} \mathrm{N}, 37^{\circ} 33^{\prime} \mathrm{E}\right.$, altitude $1080-1134 \mathrm{~m}$ above sea level (masl)] is located $30 \mathrm{~km}$ south of Wolkite near the Ghibe River. In 2016, Ghibe had 420 households with 2167 total inhabitants of whom 1105 were male and 1062 were female (Abeshge district health office, unpublished report). Darge $\left(8^{\circ} 24^{\prime} \mathrm{N}, 37^{\circ} 31^{\prime} \mathrm{E}\right.$, altitude $1500-1800$ masl) is located $42 \mathrm{~km}$ west of Wolkite and $52 \mathrm{~km}$ from Ghibe kebele on the outskirts of Darge town. The Darge River crosses Darge town and serves as one of the tributaries of the Ghibe River. In 2016, Darge had 731 households with 3518 inhabitants, of whom 1724 were male and 1794 were female (Abeshge district health office, unpublished report). In Ghibe, the majority of houses were built with thatched roofs and wooden walls plastered with mud, while in Darge they were constructed with thatched or corrugated iron roofs and wooden walls plastered with mud. The average number of occupants per house in Ghibe and Darge were 5.2 and 4.8 , respectively. The human to cattle ratio in Ghibe and Darge were 0.4 and 1.8, respectively (Abeshge District Agricultural Development Office, unpublished data). Ghibe has an annual average rainfall of $625 \mathrm{~mm}$ and Darge has 1022 mm (National Meteorological Agency, unpublished report). There was application of IRS on a yearly basis before the onset of the main rainy season, and the residents own LLINs (PermaNet ${ }^{\circledR} 2.0$ ) distributed free of charge by the Ministry of Health. 


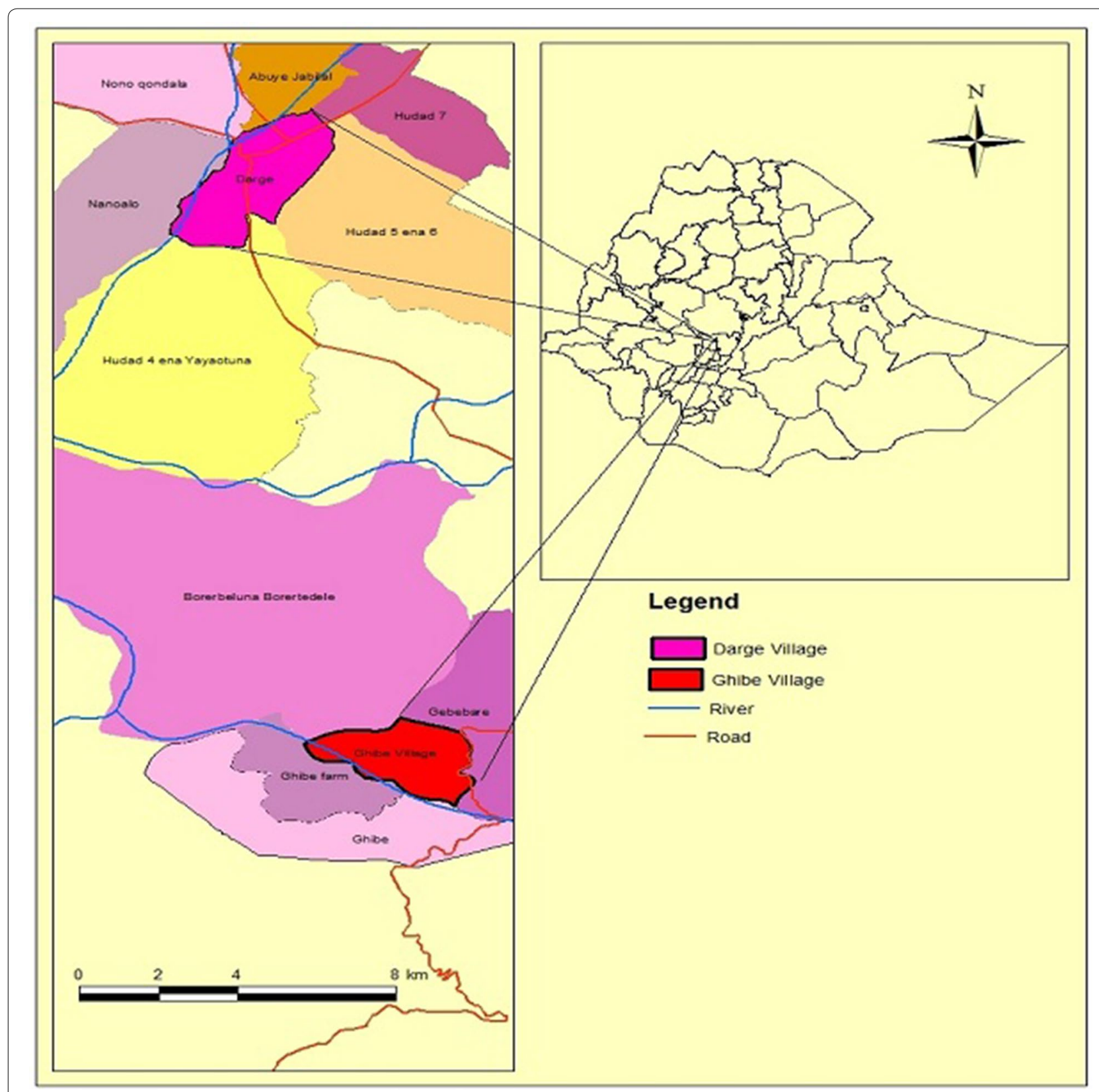

Fig. 1 Map of the study area

\section{Adult mosquito collections}

Adult Anopheles mosquitoes were collected monthly using CDC light traps, PSC, and pit shelter from each study site from January 2015 to February 2016 and April 2016 to October 2016 over 21 months. Houses were first stratified into near to $(<500 \mathrm{~m})$ and far from $(>500 \mathrm{~m})$ Ghibe and Darge rivers at Ghibe and Darge study sites, respectively. Sixteen houses (eight houses near to the river and eight houses far from the river) were selected at random for CDC light traps (BioQuip Products, Rancho
Dominguez, CA, USA) for collection of host-seeking mosquitoes indoors and outdoors. In each house, light traps were set at $1-1.5 \mathrm{~m}$ above the ground, close to the foot of an occupant sleeping under treated bednets [27]. Collections using CDC light traps were conducted starting from June 2015. For outdoor collection, light traps were hung near houses or in cattle sheds if cattle were available around homesteads. Traps were set for $12 \mathrm{~h}(18: 00 \mathrm{~h}$ in the evening to 6:00 $\mathrm{h}$ in the morning) for two sequential nights each month for a total of 1184 
trap-nights of which 672 were indoors and 512 were outdoors in each study site.

Pyrethrum spray catches and pit shelters were used to collect indoor resting and outdoor resting mosquitoes, respectively [24]. Ten houses (five houses near and five houses far from the river) were selected for spray collection for 21 months in each study site. Before the application of insecticides, all food items, drinking water and domestic animals were moved out from the house. All holes and eaves were closed with pieces of cloth. A white sheet of cloth was spread covering all the floor and furniture within the room where people had slept the previous night. Doors and windows were closed, and Baygon aerosol (prallethrin $0.10 \% \mathrm{w} / \mathrm{w}$, permethrin $0.10 \% \mathrm{w} / \mathrm{w}$; Saudi Johnson Co., Racine, WI, USA) was sprayed starting from the outside near the eaves of roof and within the house. After $10 \mathrm{~min}$, the sheet was moved out and knocked down mosquitoes were collected using forceps [28]. All collections were made in the morning (6:30 to 9:00 h). Four pit shelters (two near to the river and two far away from the river) were prepared under shade in the backyards of the households in each study site as described in Silver [29]. Mosquitoes were collected from the small cavities and from the wall of the pit itself using a hand held torch and mouth aspirator from 6:30 to 9:30 h in the morning.

Houses were purposively selected to collect blood-fed mosquitoes, by aspiration using hand-held mouth aspirator and battery-operated torch in the morning from 7:00 to 9:00. In Ghibe, livestock were kept outdoors in separate enclosures also constructed with a thatched roof and wall shelters. In Darge, it was common to keep livestock in houses with humans at night.

\section{Mosquito identification}

Female Anopheles mosquitoes were counted and sorted to abdominal conditions as unfed, freshly fed, half gravid, and gravid, and morphologically identified under stereomicroscope using morphological identification keys of Gillies and Coetzee [30]. The abdomens of freshly bloodfed Anopheles mosquitoes were used for blood meal analysis.

\section{Blood meal analysis}

Freshly blood-fed Anopheles mosquitoes were cut transversally between the thorax and abdomen beneath a dissecting microscope at 10-20× magnification. Blood meal sources were then identified using an enzyme-linked immunosorbent assay (ELISA) following the procedure described by Beier et al. [31].

\section{Malaria sporozoite ELISA}

Heads and thoraces of female Anopheles mosquitoes were processed for the detection of circumsporozoite proteins (CSP) of P. falciparum and P. vivax 210 (Pv-210) and $P$. vivax 247 (Pv-247) sporozoites using an ELISA following the procedure described in Beier et al. [32].

\section{Data analysis}

The monthly abundance of Anopheles mosquitoes in different collection methods was expressed with descriptive statistics using percentages. The monthly average density of Anopheles gambiae (s.l.) using CDC light traps, PSC and pit shelters were expressed as the total number of mosquitoes collected per total monthly catches for each sampling method. Correlation analysis was used to estimate the association between An. gambiae (s.l.) densities with rainfall. A Chi-square test was used to compare the abundance of Anopheles mosquitoes using CDC light traps between near and far houses from the river and between indoor and outdoor catches. Pit shelter and PSC samples were not included in this analysis because An. gambiae (s.l.) was the only species identified in these collection methods. The human blood index (HBI) and bovine blood index (BBI) were calculated as the ratio of blood-fed mosquitoes that had fed on humans and cattle, respectively, to the total tested. Mixed blood meal source was the ratio of blood-fed mosquitoes that had fed on both human and cattle blood to the total tested represented as a percentage. Unknown blood meal source was the ratio of blood-fed mosquitoes which contained unknown blood sources to the total tested [33] and expressed as a percentage. A Chi-square test was used to compare the differences in the HBI and BBI between indoor and outdoor collected An. gambiae (s.l.).

The sporozoite rate (SRs) is the number of mosquitoes found positive to CSP antigens divided by the total number of mosquitoes examined, expressed as a percentage [28]. The daily EIR was estimated based on CDC light trap catches and was calculated as $1.605 \times$ (number of sporozoite positive ELISAs/ number of mosquitoes tested) $\times$ (number of mosquitoes collected by CDC light trap/ number of CDC light trap catches) [34]. EIR was not estimated for mosquitoes collected with other collection methods because no CSP positive mosquitoes were identified. Monthly EIR was obtained by multiplying the daily EIR with the number of respective days of that month [35]. The monthly EIRs in each study site were summed up to calculate the annual EIR [36]. Data were analyzed using IBM SPSS statistics for Windows v.20.0 (IBM, Armonk, NY, USA). In all tests, values were considered significantly different if $P<0.05$. 


\section{Results}

\section{Composition of the Anopheles mosquitoes}

The species composition of Anopheles mosquitoes is depicted in Table 1. In total, 13 species of Anopheles mosquitoes, including An. gambiae (s.l.), Anopheles coustani, Anopheles pretoriensis, Anopheles demeilloni, Anopheles rupicolus, Anopheles christyi, An. pharoensis, An. nili and Anopheles rivulorum were collected in both Ghibe and Darge study sites, whereas Anopheles tenebrosus, Anopheles ardensis, Anopheles natalensis, and Anopheles zeimanni were recorded only in Ghibe. Anopheles gambiae (s.l.) was the predominant species in both study sites (87.9\% in Ghibe and $67.7 \%$ in Darge) followed by $A n$. coustani (5.4\% in Ghibe and 14.3\% in Darge) (Table 1).

Among the collection methods used, all of the identified Anopheles species were represented in CDC light trap collections. Only An. gambiae (s.l.) mosquitoes were collected by PSC and hand collections with mouth aspirators from inside houses. Anopheles gambiae (s.l.) and An. pretoriensis were collected from pit shelter outdoors, while An. gambiae (s.l.) and An. coustani were collected using mouth aspirators from cattle sheds. All identified species were collected from indoors and outdoors, except An. tenebrosus, An. natalensis, An. ziemanni and $A n$. nili, which were sampled only outdoors. About $69 \%$ of Anopheles mosquitoes were collected using CDC light traps (Table 1).

In Ghibe, the mean density of An. gambiae (s.l.) using CDC light traps was higher outdoors (1.8/CDC light trap/ night) than indoors (0.7/CDC light trap/night) (Fig. 2). The largest proportions of monthly densities of An. gambiae (s.l.) using CDC light traps indoors were 4.1/CDC light trap/night and in outdoor catches were 6.7/CDC light trap/night. The density of this species in PSC was higher in August 2016 (2/house/day) and in pit shelter it was in November 2015 (14.8/pit shelter/day). In Darge, the mean density of An. gambiae (s.l.) was $0.125 / \mathrm{CDC}$ light trap/night indoors and $0.07 / C D C$ light trap/night outdoors. The largest proportions of monthly density of An. gambiae (s.l.) using CDC light trap indoors was 0.69/ CDC light trap/night in August, and in outdoor catches was $0.41 / C D C$ light trap/night in July 2015 and August 2016 (Fig. 3). However, using PSC and pit shelters, only $0.01 /$ house/day and $0.67 /$ pit shelter/day were captured. Anopheles gambiae (s.l.) density was not significantly correlated with rainfall in Ghibe [CDC light trap $r_{(21)}=0.388$, $P=0.082 ; \quad$ PSC $\quad r_{(21)}=0.324 ; \quad P=0.152 ;$ pit shelter $r_{(21)}=-0.156, P=0.499$ ] and in Darge [CDC light trap $r_{(21)}=0.204, P=0.374$; PSC $r_{(21)}=0.395, P=0.076$; pit shelter $\left.r_{(21)}=-0.037, P=0.873\right]$. Figures 2,3 show that mosquito population starts to build up immediately after the rains. Analysis to compare Anopheles mosquito densities from near and far houses from the river was based on data collected using CDC light traps from June 2015 to October 2016 due to the start of outdoor collection in June 2015 (Table 2). Anopheles ardensis, An. natalensis, An. ziemanni, An. nili, An. rivulorum and unidentified species were excluded from this analysis because of their low numbers. Among the remaining Anopheles mosquitoes sampled in Ghibe, significantly more were caught outdoors $(n=1157 ; 72.0 \%)$ than indoors $(n=450$; $28.0 \%)$ (Table 2) $\left(\chi^{2}=49.037, d f=7, P<0.001\right)$ and significantly more Anopheles were caught in houses closer to the river $(n=1350 ; 84.0 \%)$ than in houses located far from the river $(n=257 ; 16.0 \%)\left(\chi^{2}=113.038, d f=7\right.$, $P<0.001)$. Similarly, in Darge, significantly more Anopheles mosquitoes were sampled outdoors $(n=101 ; 54.6 \%)$ than indoors $(n=84 ; 45.4 \%)$ (Table 2$)\left(\chi^{2}=39.902, d f=4\right.$, $P<0.001)$, and significantly more Anopheles mosquitoes were caught in houses near to the river $(n=127 ; 68.6 \%)$ than far from the river $(n=58 ; 31.4 \%)\left(x^{2}=30.759, d f=4\right.$, $P<0.001)$.

\section{Blood-feeding status of adult Anopheles mosquitoes}

With the exception of 87 (3.3\%) Anopheles mosquitoes, the abdominal conditions of all were classified into unfed, freshly fed, half gravid and gravid (Table 3). From mosquitoes collected using CDC light trap, among their abdominal conditions identified $67.7 \%(n=1195)$ were unfed and only $22.5 \%(n=398)$ were blood-fed. From PSC, there were no unfed and $51.3 \%(n=20)$ were bloodfed, $30.8 \%(n=12)$ were half gravid and $17.9 \%(n=7)$ were gravid, but $57.3 \%(n=355)$ of mosquitoes collected with mouth aspirator were blood-fed and only $3.9 \%$ $(n=24)$ were unfed. Catches from pit shelter showed $38.0 \%(n=60)$ were blood-fed but lower proportion $(12.7 \%, n=20)$ of unfed mosquitoes were collected.

\section{Blood meal sources and blood indices}

Human blood was identified from An. gambiae (s.l.), An. coustani, An. demeilloni and An. nili and no other species of Anopheles mosquitoes were identified as having fed on humans (Table 4). Human and cattle mixed blood was detected from An. gambiae (s.l.) and An. demeilloni. More than $35 \%$ of the blood meal sources of An. gambiae (s.l.) collected outdoors using CDC light traps were not known (not fed on humans or cattle) (Table 4).

In Ghibe, the HBI for An. gambiae (s.l.) was $58.0 \%$ from CDC light trap collections indoor and $16.0 \%$ outdoor. The BBI from CDC light trap collections indoor was $14.0 \%$ and in outdoor was $47.0 \%$. There was significant difference between indoor and outdoor catches in their blood meal sources $\left(\chi^{2}=42.134, d f=3, P<0.001\right)$. The HBI was $75.0 \%$ from PSC. Mixed blood (human and cattle) sources for An. gambiae (s.l.) using CDC light trap 


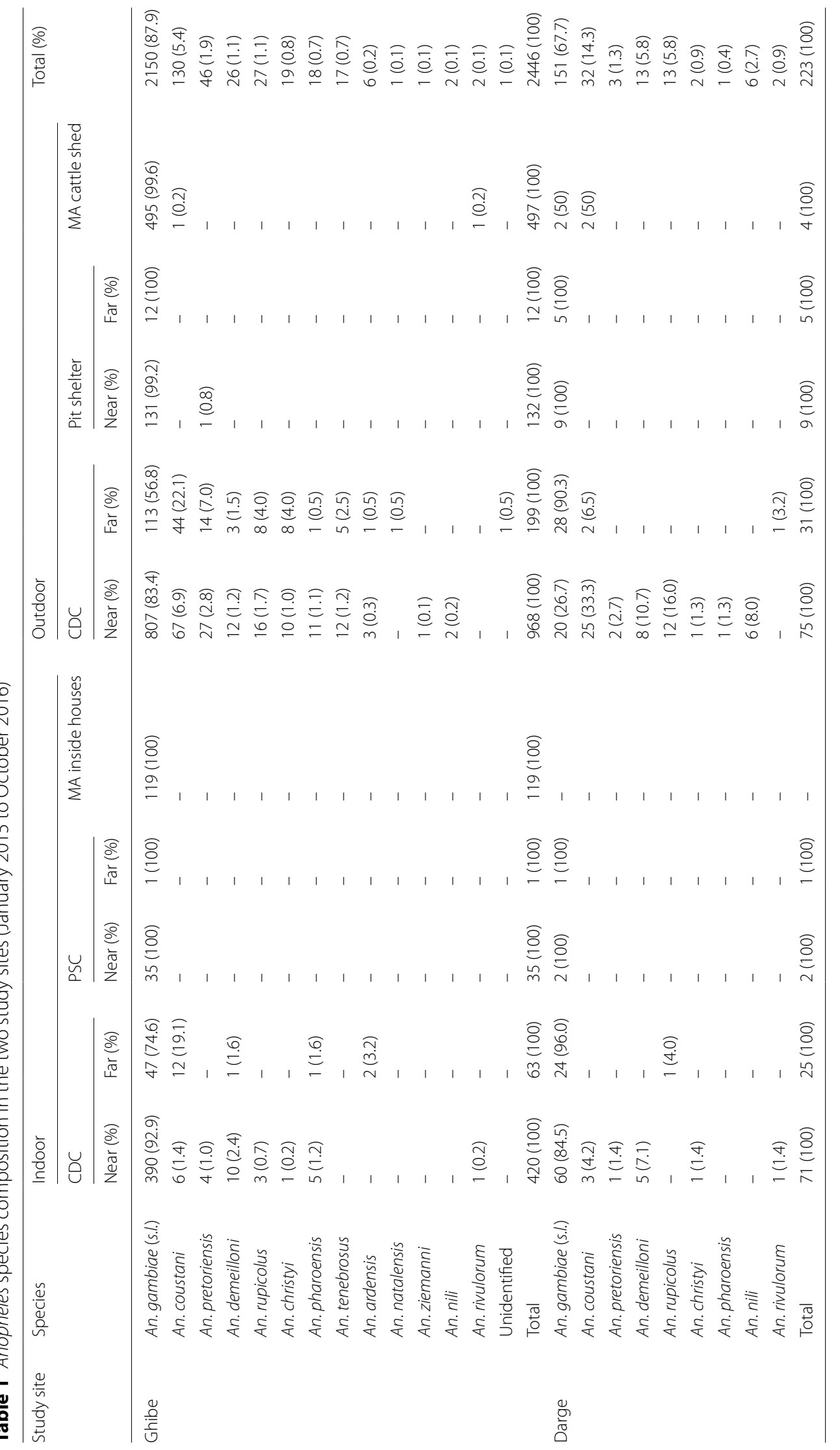



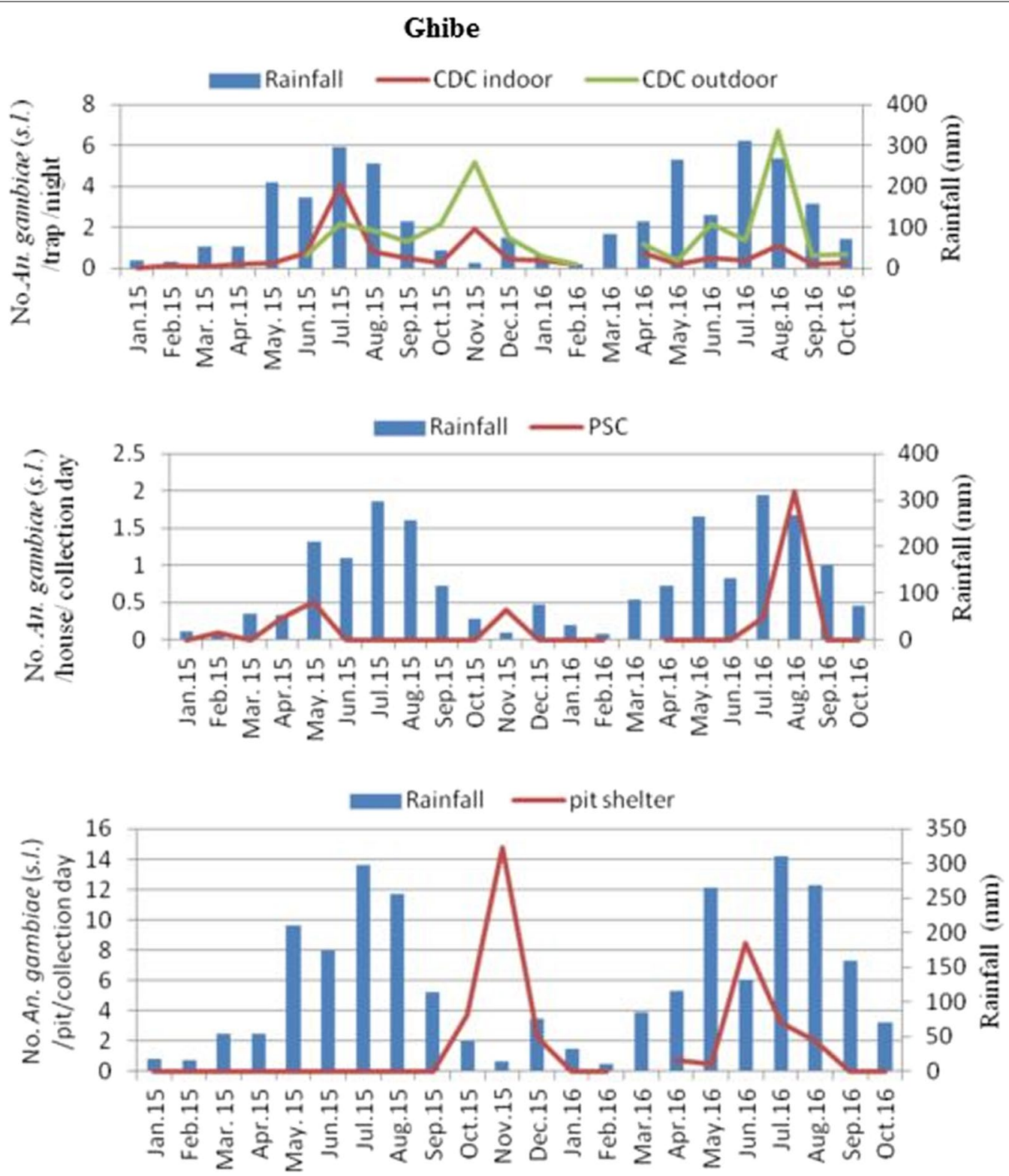

Fig. 2 Monthly density of An. gambiae (s.l.) and its association with rainfall (in $\mathrm{mm}$ ) in the Ghibe study site

indoor, CDC light trap outdoor and PSC were 4.4, 1.3 and $5.0 \%$, respectively.

In Darge, the HBI of An. gambiae (s.l.) from CDC light trap collections indoors and outdoors was 14.0 and $13.0 \%$, respectively, while the $\mathrm{BBI}$ was higher both indoor (57.0\%) and outdoor (50.0\%) than that of HBI. However, there was no significant difference between HBI or BBI of An. gambiae (s.l.) caught indoors and outdoors $\left(\chi^{2}=0.216, d f=2, P=0.898\right)$.

In Ghibe, the BBI of An. gambiae (s.l.) collected from pit shelters and mouth aspirated from cattle sheds was 83.0 and $68.0 \%$, respectively, and the HBI using mouth aspirators from human dwellings was 74.0\% (Table 5). Although the proportion was low, human blood-fed and mixed blood-fed mosquitoes were also identified from pit shelters and cattle sheds. In Darge, all of the tested mosquitoes collected from cattle sheds had fed on cattle.

In total, 1801 Anopheles mosquitoes (1668 from Ghibe and 133 from Darge) belonging to 12 species were tested for Plasmodium CSP using ELISA. Of these 1620 (90\%) were An. gambiae (s.l.) (Table 6). Out of the total tested, sporozoites were detected only in two of the An. gambiae (s.l.) (one P. vivax, i.e. 

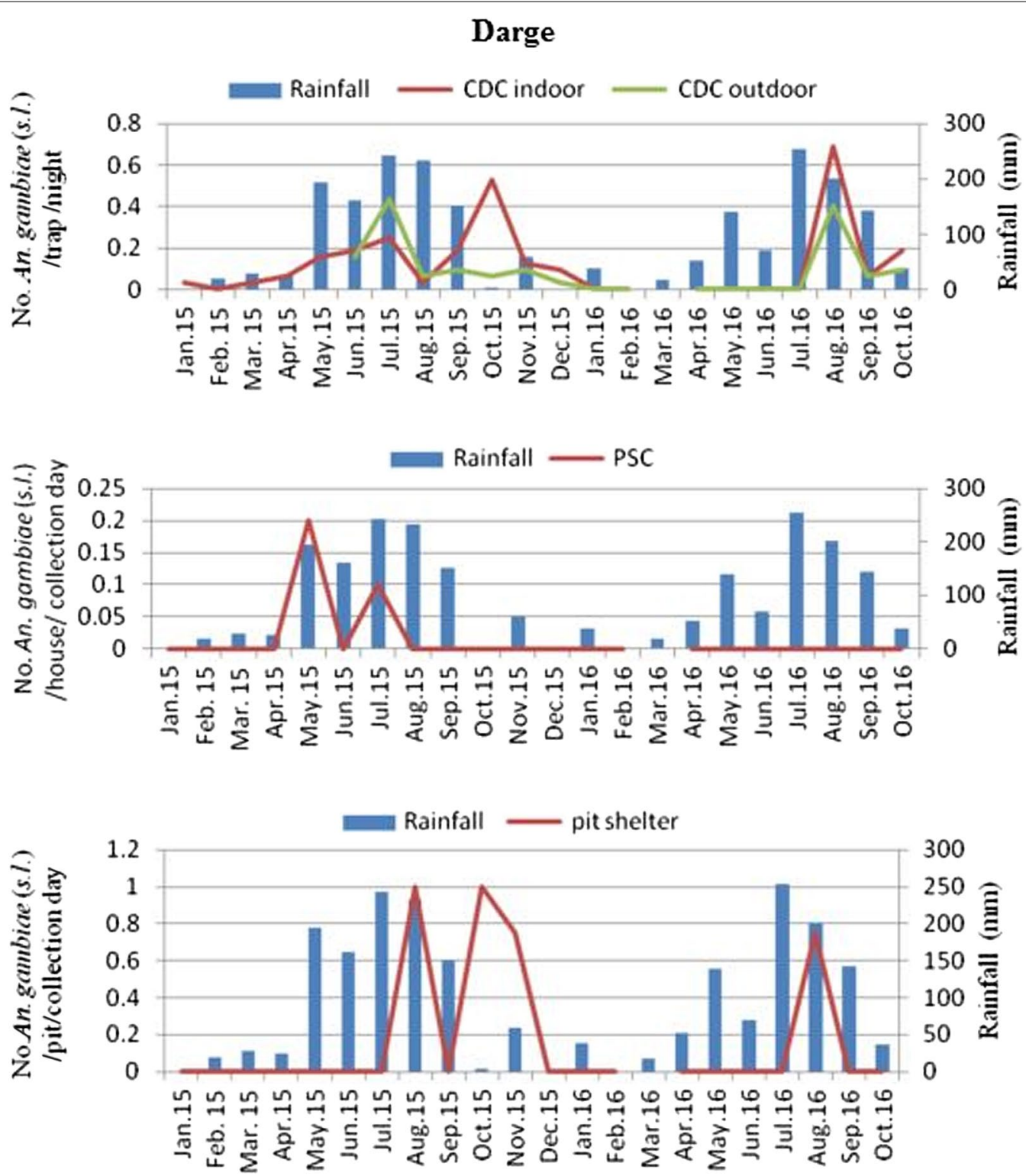

Fig. 3 Monthly density of An. gambiae (s.l.) and its association with rainfall (in $\mathrm{mm}$ ) in the Darge study site

Pv-210, and one P. falciparum) collected using CDC light traps. All the other Anopheles mosquitoes species tested were negative for Plasmodium infection. Sporozoite rates were $0.07 \%$ for $P$. vivax and $0.07 \%$ for $P$. falciparum in An. gambiae (s.l.) tested in Ghibe and zero in Darge. Anopheles gambiae (s.l.) tested had overall $P$. vivax and P. falciparum sporozoite rates of $0.06 \%$ each.

In Ghibe, the overall EIRs for $P$. falciparum and $P$. vivax were zero and 8.4 infective bites/person/year, respectively, for the year 2015, while zero and 5.4 infective bites/person/year for $P$. vivax and $P$. falciparum, respectively, for the year 2016 (Table 7). No
Plasmodium-positive Anopheles mosquitoes were identified from Darge so that EIR was not analyzed.

\section{Discussion}

Anopheles gambiae (s.l.) was the predominant species in the study area followed by An. coustani. A study by Tekie [37] in the area also showed that An. gambiae (s.l.) was the predominant species. Similarly, other studies conducted in Ethiopia showed that An. arabiensis [member of An. gambiae (s.l.)] was the most abundant species in the country $[23,38,39]$. However, a study in Edo Kontola village, south-central Ethiopia, found that An. ziemanni 
Table 2 Comparison of Anopheles abundance collected indoor or outdoor and in houses near or far from the rivers

\begin{tabular}{|c|c|c|c|c|c|c|c|}
\hline \multirow[t]{2}{*}{ Study site } & \multirow[t]{2}{*}{ Species } & \multicolumn{3}{|c|}{ CDC light trap catch indoor } & \multicolumn{3}{|c|}{ CDC light trap catch outdoor } \\
\hline & & Near (\%) & Far (\%) & Total & Near (\%) & Far (\%) & Total \\
\hline \multirow[t]{9}{*}{ Ghibe } & An. gambiae (s.l.) & $367(89.1)$ & 45 (10.9) & 412 & $805(87.5)$ & $115(12.5)$ & 920 \\
\hline & An. coustani & $7(36.8)$ & $12(63.2)$ & 19 & $66(60.0)$ & $44(40.0)$ & 110 \\
\hline & An. demeilloni & $10(90.9)$ & $1(9.1)$ & 11 & $12(80.0)$ & $3(20.0)$ & 15 \\
\hline & An. rupicolus & $3(100)$ & - & 3 & $16(66.7)$ & $8(33.3)$ & 24 \\
\hline & An. christyi & $1(100)$ & - & 1 & $10(55.6)$ & $8(44.4)$ & 18 \\
\hline & An. pretoriensis & $1(100)$ & - & 1 & $27(65.9)$ & $14(34.1)$ & 41 \\
\hline & An.pharoensis & $2(66.7)$ & $1(33.3)$ & 3 & $11(91.7)$ & $1(8.3)$ & 12 \\
\hline & An. tenebrosus & - & - & - & $12(70.6)$ & $5(29.4)$ & 17 \\
\hline & Total & $391(86.9)$ & $59(13.1)$ & 450 & $959(82.9)$ & $198(17.1)$ & 1157 \\
\hline \multirow[t]{6}{*}{ Darge } & An. gambiae (s.l.) & $48(64.0)$ & $27(36.0)$ & 75 & $20(41.7)$ & $28(58.3)$ & 48 \\
\hline & An. coustani & $3(100)$ & - & 3 & 25 (92.6) & $2(7.4)$ & 27 \\
\hline & An. demeilloni & $5(100)$ & - & 5 & $8(100)$ & - & 8 \\
\hline & An. rupicolus & - & $1(100)$ & 1 & $12(100)$ & - & 12 \\
\hline & An. nili & - & - & - & $6(100)$ & - & 6 \\
\hline & Total & $56(66.7)$ & $28(33.3)$ & 84 & $71(70.3)$ & $30(29.7)$ & 101 \\
\hline
\end{tabular}

Table 3 Abdominal status of Anopheles mosquitoes collected by different methods in the study sites

\begin{tabular}{|c|c|c|c|c|c|c|c|c|c|c|c|c|c|c|c|c|c|}
\hline \multirow[t]{2}{*}{ Species } & \multicolumn{5}{|l|}{$\mathrm{CDC}$} & \multicolumn{3}{|c|}{ PSC } & \multicolumn{4}{|c|}{ Pit shelter } & \multicolumn{4}{|c|}{ Mouth aspirator } & \multirow[t]{2}{*}{ Total } \\
\hline & UF & $\mathrm{FF}$ & $H G$ & $G R$ & UN & $\mathrm{FF}$ & $H G$ & $G R$ & UF & $\mathrm{FF}$ & $H G$ & GR & UF & $\mathrm{FF}$ & $H G$ & $G R$ & \\
\hline An. gambiae (s.l.) & 1060 & 218 & 71 & 79 & 61 & 20 & 12 & 7 & 19 & 60 & 51 & 27 & 24 & 351 & 138 & 103 & 2301 \\
\hline An. coustani & 79 & 72 & - & 1 & 10 & - & - & - & - & - & - & - & - & 3 & - & - & 162 \\
\hline An. pretoriensis & 8 & 35 & 1 & 2 & 2 & - & - & - & 1 & - & - & - & - & - & - & - & 49 \\
\hline An. rupicolus & 15 & 22 & 2 & - & 1 & - & - & - & - & - & - & - & - & - & - & - & 40 \\
\hline An. demeilloni & 14 & 18 & 2 & 2 & 3 & - & - & - & - & - & - & - & - & - & - & - & 39 \\
\hline An. christyi & 3 & 14 & - & 1 & 3 & - & - & - & - & - & - & - & - & - & - & - & 21 \\
\hline An. pharoensis & 3 & 7 & 4 & 5 & - & - & - & - & - & - & - & - & - & - & - & - & 19 \\
\hline An.tenebrosus & 6 & 9 & - & 1 & 1 & - & - & - & - & - & - & - & - & - & - & - & 17 \\
\hline An. nili & 2 & 3 & - & - & 3 & - & - & - & - & - & - & - & - & - & - & - & 8 \\
\hline An. ardensis & 2 & 1 & - & 1 & 2 & - & - & - & - & - & - & - & - & - & - & - & 6 \\
\hline An. rivulorum & 2 & 1 & - & - & - & - & - & - & - & - & - & - & - & 1 & - & - & 4 \\
\hline An. ziemanni & - & - & - & - & 1 & - & - & - & - & - & - & - & - & - & - & - & 1 \\
\hline An. natalensis & - & 1 & - & - & - & - & - & - & - & - & - & - & - & - & - & - & 1 \\
\hline Unidentified & 1 & - & - & - & - & - & - & - & - & - & - & - & - & - & - & - & 1 \\
\hline Total & 1195 & 398 & 80 & 92 & 87 & 20 & 12 & 7 & 20 & 60 & 51 & 27 & 24 & 355 & 138 & 103 & 2669 \\
\hline
\end{tabular}

Abbreviations: PSC, Pyrethrum spray sheet collection; MA, mouth aspirator; UF, unfed; FF, fresh fed; $\mathrm{HF}$, half gravid; GR, gravid; UN, abdominal status unknown

was the predominant species followed by An. arabiensis; these observed differences could be explained by variation in available larval breeding sites that support the development of the former species [40].

More Anopheles mosquitoes were sampled outdoors using CDC light traps, pit shelters and mouth aspirators than indoors. The human landing catch in Ghibe Horticulture Development Farm showed An. gambiae (s.l.) bites human both indoors and outdoors [37]. This outdoor abundance of Anopheles mosquitoes could be attributed to females having left houses immediately after feeding indoors [41], increased outdoor biting due to the availability of cattle outside houses [42, 43], vector control interventions targeting indoor biting and resting mosquitoes that induced exophagic and late biting behavior [40, 44-47], or rapid exit after entering houses $[13,47]$. The availability of cattle outdoors might enhance outdoor catches using CDC light traps, thus extending 


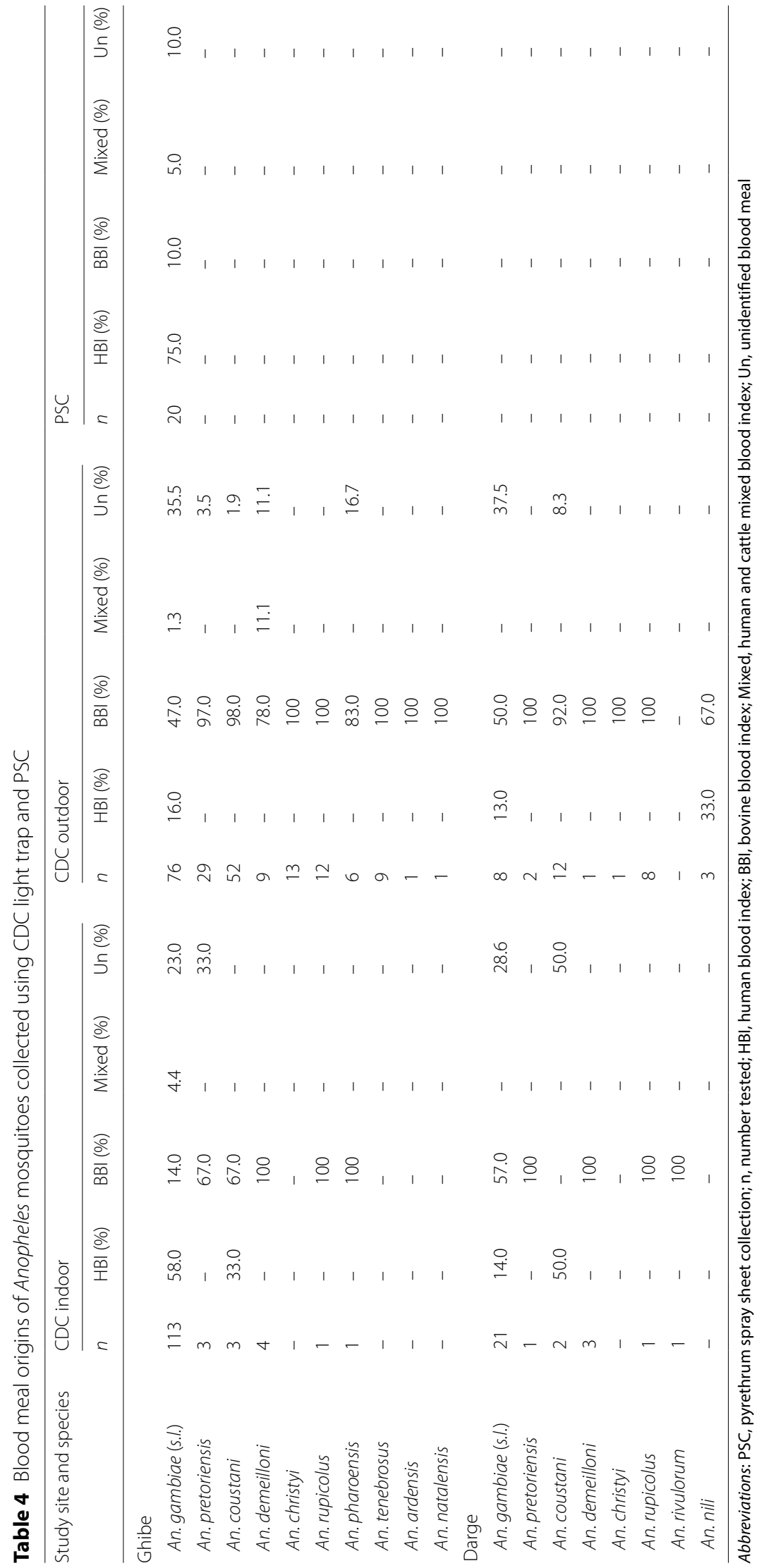


Table 5 Blood meal origins of An. gambiae (s.l.) mosquitoes collected using pit shelter and mouth aspirator

\begin{tabular}{llllll}
\hline Collection method & $n$ & HBI (\%) & BBI (\%) & Mixed (\%) & Un (\%) \\
\hline Pit shelter & 60 & 3.0 & 83.0 & 1.7 & 11.7 \\
MA human house & 58 & 74.0 & 14.0 & - & 12.1 \\
MA cattle shed & 291 & 2.0 & 68.0 & 0.7 & 29.6 \\
\hline
\end{tabular}

Abbreviations: $\mathrm{MA}$, mouth aspirator; $\mathrm{n}$, number tested; $\mathrm{HBI}$, human blood index; $\mathrm{BBI}$, bovine blood index; Mixed, human and cattle mixed blood index; Un, unidentified blood meal

the host-seeking flight period, which in turn increases the chance of getting caught in the trap [48]. However, a study conducted in Lake Victoria, Kenya, sampled higher numbers of Anopheles mosquitoes indoors than outdoors in villages with low LLIN coverage than those with high coverage [49].

Low densities of Anopheles mosquitoes were collected from Darge as compared to Ghibe. The possible reasons could be attributed to the difference in the type of house construction materials [50,51], variation in proportions of cattle owned by the residents [43], altitudinal variation between the two study sites [38] or availability of breeding habitat during the study period [52]. Anopheles gambiae (s.l.) density was not significantly correlated with rainfall. This might be attributed to the spraying of houses with insecticides before the onset of the main rain or that the larval habitat could be affected due to heavy rain or formed after rains. Our study also showed that Anopheles mosquitoes were more abundant in houses closer to the river (within $500 \mathrm{~m}$ distance) than in houses far away from the river. In agreement with our results, a study in western Kenya highlands [50] and Iguhu Village, western Kenya [53], showed that houses located closer to the vector habitats had a significantly higher distribution of adult mosquitoes than those farther away. Residents near to the major vector-breeding sites were also observed to be more affected by malaria in urban Uganda [54] and Adama town, in Ethiopia [55], as compared to residents far from breeding sites.

Our study showed that in Ghibe, HBI was higher from mosquitoes collected indoors from human dwellings, while BBI was higher from outdoor collections, which is in agreement with findings of Hadis et al. [56] and Massebo et al. [57]. In contrast to our result, other studies found that the HBI of An. arabiensis collected indoors and outdoors were not different, but BBI was higher among indoor than outdoor collected mosquitoes [33], and mosquitoes collected outdoors had a higher HBI than those collected indoors [58]. It was suggested that people might be bitten more frequently outdoors, or that indoor-biting mosquitoes do not remain inside and instead exit houses after feeding
$[41,58]$ or might also bite in the early evening indoors and outdoors at times when the local people were not protected by LLINs [16, 40, 47]. However, in Darge there was no significant difference between BBI in CDC light trap set indoors and outdoors. It was observed that people share houses with cattle in Darge so that mosquitoes may bite cattle indoors. The presence of domesticated animals in the same houses with humans at night likely plays a key role in blood-feeding from humans and animals by local malaria vectors [59].

The availability of alternative hosts like cattle can significantly affect the resting and feeding preference of Anopheles mosquitoes at the household level [43, $49,57,59]$. A study in costal Kenya showed that the primary malaria vectors have shifted from feeding on humans to animals, coinciding with the mass distribution of LLINs in the area $[46,59]$. Animals are considered as a dead end for human malaria pathogens [46, 59] and zooprophylactic agents for zoophagic vectors like An. arabiensis [60]. Hence, in areas where An. arabiensis (which has zoophagic behavior) is the major malaria vector, the use of cattle treated with insecticides could be helpful for their control [61, 62]. New control tools that target mosquitoes biting outdoors and early at night before people go to bed are urgently required to control malaria in combination with the existing control interventions [14].

The sporozoite rate for $A n$. gambiae (s.l.) was very low (0.07\% for $P$. vivax and $P$. falciparum in Ghibe and zero in Darge) as compared to 1.5 and $0.3 \%$ for $P$. falciparum and P. vivax, respectively, in the suburbs of Jimma town [63], $1.18 \%$ for $P$. falciparum in the Zway area, central Ethiopia [17], and $4.1 \%$ in lowland areas around dams in Ethiopia [19]. These observed differences in sporozoite rates could be explained by the variation in sampling season of Anopheles mosquitoes in which mosquito collection was during peak malaria transmission season or due to availability of small-scale irrigation or dam construction in the previous studies. In-line with the study conducted in south-central Ethiopia [38], our study revealed that Plasmodium infections were detected in An. gambiae (s.l.) collected at the end of short rainy season (May) and long rainy season (October). However, An. arabiensis and $A n$. pharoensis were found infected with $P$. falciparum sporozoites both in the dry and short rainy seasons in areas with irrigation scheme of Zway [17].

Our study revealed that the annual EIR was very low (8.4 infective bites/person/year for P. vivax and 5.4 infective bites/person/year for $P$. falciparum) in Ghibe and was zero in Darge during the study period. One possible explanation is an extended period of low rainfall during the study period [36]. A recent study showed that EIR of An. arabiensis collected near a dam constructed at 


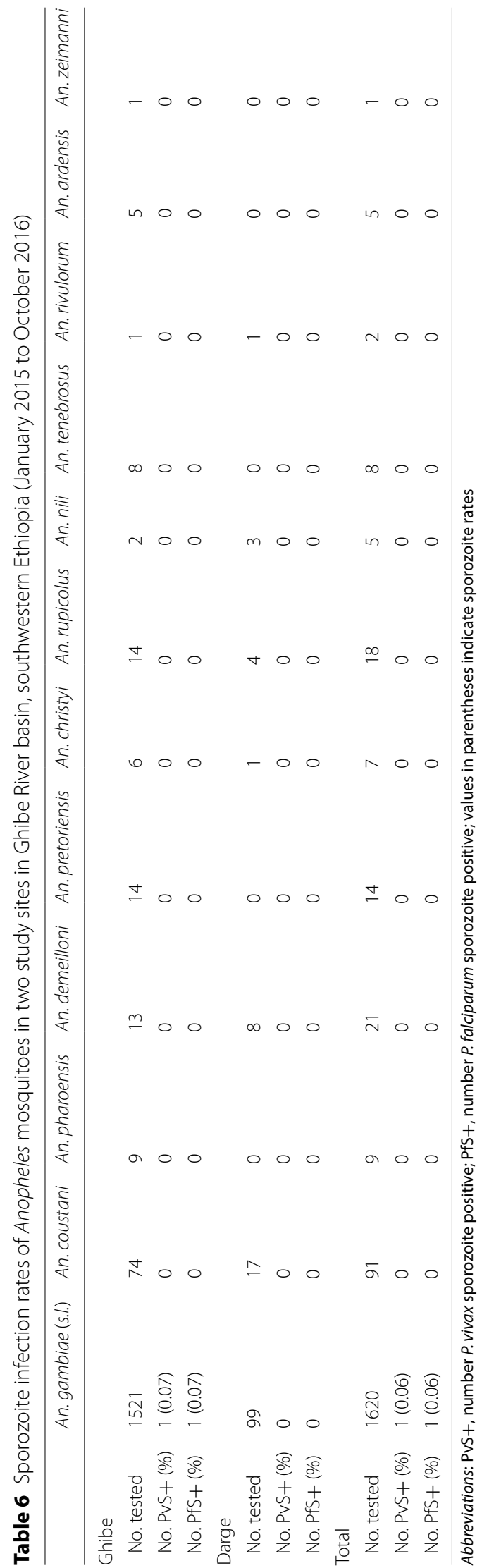


Table 7 Sporozoite rate and EIR of An. gambiae (s.l.) in Ghibe study site of Ghibe River basin, southwestern Ethiopia (January 2015 to October 2016)

\begin{tabular}{lllll}
\hline Month-year & Daily PvSR & Monthly PvEIR & Daily PfSR & Monthly PfEIR \\
\hline Jan-15 & 0 & 0 & 0 & 0 \\
Feb-15 & 0 & 0 & 0 & 0 \\
Mar-15 & 0 & 0 & 0 & 0 \\
Apr-15 & 0 & 0 & 0 & 0 \\
May-15 & 0 & 0 & 0 & 0 \\
Jun-15 & 0 & 0 & 0 & 0 \\
Jul-15 & 0 & 0 & 0 & 0 \\
Aug-15 & 0 & 0 & 0 & 0 \\
Sep-15 & 0 & 0 & 0 & 0 \\
Oct-15 & 0.09 & 8.4 & 0 & 0 \\
Nov-15 & 0 & 0 & 0 & 0 \\
Dec-15 & 0 & 0 & 0 & 0 \\
2015 total & 0.09 & 8.4 & 0 & 0 \\
Jan-16 & 0 & 0 & 0 & 0 \\
Feb-16 & 0 & 0 & 0 & 0 \\
Apr-16 & 0 & 0 & 0 & 0 \\
May-16 & 0 & 0 & 0.1 & 5.4 \\
Jun-16 & 0 & 0 & 0 & 0 \\
Jul-16 & 0 & 0 & 0 & 0 \\
Aug-16 & 0 & 0 & 0 & 0 \\
Sep-16 & 0 & 0 & 0 & 0 \\
Oct-16 & 0 & 0 & 0 & 0 \\
2016 total & 0 & 0 & 0.1 & 5.4 \\
\hline Abbriatins: PVR Pviax & 0 . & 0 & 0 \\
\hline
\end{tabular}

Abbreviations: $\mathrm{PvSR}$, P. vivax sporozoite rate; $\mathrm{PvEIR}$, $P$. vivax entomologic inoculation rate; PfSR, P. falciparum sporozoite rate; PfEIR, P. falciparum entomological inoculation rate, results in bold showed annual EIR

lowland area was very high, with a value of 129.8 infective bites/person/year [19]. Studies also showed that variation in EIR could be observed between the periphery and the center within the same town $[34,63]$.

Although malaria prevalence was low in the study area, the annual EIR was not zero infective bites/person/year in Ghibe but zero in Darge. A study in south-central Ethiopia showed that all tested Anopheles mosquitoes were negative for $P$. falciparum and $P$. vivax CSP $[15,39]$. In some locations, a few people might be bitten multiple times by mosquitoes and may remain infected, although overall prevalence falls in a population. Most mosquitoes become infected when they bite this group of people and likely not if they bite others [64].

This line of study may further be improved upon in future studies with the incorporation of a window exit trap to study the indoor feeding and resting behavior of Anopheles mosquitoes as they leave the houses after feeding and/or resting. For the determination of blood meal sources of Anopheles mosquitoes in the study area, they were tested only for identifying human or cattle blood sources, which likely missed other animals that serve as alternative blood meal sources [49].

\section{Conclusions}

Anopheles gambiae (s.l.), which is considered as the main malaria vector in Ethiopia, was the predominant species in the study area. This species of mosquitoes was collected both indoors and outdoors. Blood meal analysis showed that they fed both on humans and cattle. Anopheles mosquitoes were abundant in houses located closer to the river as compared to houses far away from the river. In determining malaria risks, vector control strategies targeted to houses closer to the river could have great importance in malaria reduction. It might be difficult to control malaria with the current vector control interventions due to the availability of malaria vectors both indoors and outdoors. Thus, additional measures need to be considered to effectively reduce their numbers outdoors.

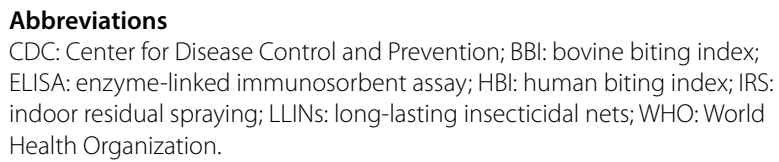

\section{Acknowledgements}

We would like to thank all the community members of the Ghibe and Darge study sites for participating in this study and allowing mosquito collections from their premises. We appreciate the assistance provided by Ghibe seed enterprise in offering rooms for living and mosquito processing. Great thanks to Dr Oljira Kenea for technical assistance in blood meal ELISA. We would also like to thank Dr Seth R. Irish for his support in providing reagent and chemicals important for the blood meal ELISA. We would like to acknowledge Addis Ababa University and Dire Dawa University for financial support.

\section{Authors' contributions}

DG, TGM, MB and HT conceived and designed the study; DG conducted field work and laboratory experiments, analyzed and interpreted the data, wrote the manuscript; and TGM, MB and HT supervised. All authors read and approved the final manuscript.

\section{Funding}

This study was financially supported by Addis Ababa University and Dire Dawa University. The funding bodies were not involved in the design of the study and data collection, analysis, and interpretation of data and in writing the manuscript.

\section{Availability of data and materials}

The data sets generated and/or analyzed during the present study are available from the corresponding author upon reasonable request.

\section{Ethics approval and consent to participate}

Approval to conduct the study was obtained from the ethical committee of College of Natural Sciences Institutional Ethics Review Board, Addis Ababa University. Consent was also obtained from Abeshge district (woreda) administration and the manager of each study site after the purpose of the investigation was explained to them. Verbal consent was obtained from each household head of selected houses where mosquitoes were sampled from their houses or their premises in each study site. 


\section{Competing interests}

The authors declare they have no competing interests.

\section{Author details}

${ }^{1}$ Department of Biology, Dire Dawa University, P. O. Box 1362, Dire Dawa, Ethiopia. ${ }^{2}$ Department of Zoological Sciences, Addis Ababa University, P. O. Box 1176, Addis Ababa, Ethiopia. ${ }^{3}$ Aklilu Lemma Institute of Pathobiology, Addis Ababa University, P. O. Box 1176, Addis Ababa, Ethiopia. ${ }^{4}$ Abt Associates, PMI VectorLink Ethiopia Project, Addis Ababa, Ethiopia.

Received: 4 January 2019 Accepted: 9 May 2019

\section{Published online: 23 May 2019}

\section{References}

1. WHO. World malaria report 2017. Geneva: World Health Organization; 2017

2. FMoH. Ethiopia National Malaria Indicator Survey 2015. Addis Ababa: Federal Democratic Republic of Ethiopia, Ministry of Health; 2016.

3. WHO. World malaria report 2016. Geneva: World Health Organization; 2016

4. Abeku TA. Response to malaria epidemics in Africa. Emerg Infect Dis. 2007:13:681-6.

5. Woyessa A, Gebre-Micheal T, Ali A. An indigenous malaria transmission in the outskirts of Addis Ababa, Akaki Town and its environs. Ethiop J Health Dev. 2004;18:2-7.

6. Alemu A, Muluye D, Mihret M, Adugna M, Gebeyaw M. Ten year trend analysis of malaria prevalence in Kola Diba, North Gondar, Northwest Ethiopia. Parasit Vectors. 2012;5:173.

7. Sena LD, Deressa WA, Ali AA. Analysis of trend of malaria prevalence in south-west Ethiopia: a retrospective comparative study. Malar J. 2014;13:188.

8. Abeku TA, van Oortmarssen GJ, Borsboom G, de Vlas SJ, Habbema JDF. Spatial and temporal variations of malaria epidemic risk in Ethiopia: factors involved and implications. Acta Trop. 2003;87:331-40.

9. Jima D, Getachew A, Bilak H, Steketee RW, Emerson PM, Graves PM, et al. Malaria indicator survey 2007, Ethiopia: coverage and use of major malaria prevention and control interventions. Malar J. 2010;9:58.

10. Aregawi M, Lynch M, Bekele W, Kebede H, Jima D, Taffese HS, et al. Time series analysis of trends in malaria cases and deaths at hospitals and the effect of antimalarial interventions, 2001-2011, Ethiopia. PLoS ONE. 2014;9:e106359

11. $\mathrm{FMoH}$. Entomological profile of malaria in Ethiopia. Addis Ababa: Federal Ministry of Health; 2007.

12. Breman JG, Brandling-Bennett AD. The challenge of malaria eradication in the twenty-first century: research linked to operations is the key. Vaccine. 2011;29S:D97-103.

13. Killeen GF. Characterizing, controlling and eliminating residual malaria transmission. Malar J. 2014;13:330

14. Govella NJ, Ferguson H. Why use of interventions targeting outdoor biting mosquitoes will be necessary to achieve malaria elimination. Front Physiol. 2012;13:199.

15. Kenea O, Balkew M, Tekie H, Gebre-Michael T, Deressa W, Loha E, et al. Human-biting activities of Anopheles species in south-central Ethiopia. Malar J. 2016;9:527

16. Yohannes $M$, Boelee E. Early biting rhythm in the afro-tropical vector of malaria, Anopheles arabiensis, and challenges for its control in Ethiopia. Med Vet Entomol. 2012:26:103-5.

17. Kibret S, Alemu Y, Boelee E, Tekie H, Alemu D, Petros B. The impact of a small-scale irrigation scheme on malaria transmission in Ziway area, Central Ethiopia. Trop Med Int Health. 2010;15:41-50.

18. Kibret S, Wilson GG, Tekie H, Petros B. Increased malaria transmission around irrigation schemes in Ethiopia and the potential of canal water management for malaria vector control. Malar J. 2014;13:360.

19. Kibret S, Wilson GG, Ryder D, Tekie H, Petros B. Malaria impact of large dams at different eco-epidemiological settings in Ethiopia. Trop Med Health. 2017:45:4.

20. Tadesse FG, Pett H, Baidjoe A, Lanke K, Grignard L, Sutherland C, et al. Submicroscopic carriage of Plasmodium falciparum and Plasmodium vivax in a low endemic area in Ethiopia where no parasitaemia was detected by microscopy or rapid diagnostic test. Malar J. 2015;14:303.

21. Balkew M, Ibrahim M, Koekemoer LL, Brooke BD, Engers H, Aseffa A, et al. Insecticide resistance in Anopheles arabiensis (Diptera: Culicidae) from villages in central, northern and south west Ethiopia and detection of $k d r$ mutation. Parasit Vectors. 2010;3:40.

22. Yewhalaw D, Wassie F, Steurbaut W, Spanoghe P, Van Bortel W, Denis L, et al. Multiple insecticide resistance: an impediment to insecticide-based malaria vector control program. PLoS ONE. 2011;6:e16066.

23. Massebo F, Balkew M, Gebre-Michael T, Lindtjørn B. Blood meal origins and insecticide susceptibility of Anopheles arabiensis from Chano in South-West Ethiopia. Parasit Vectors. 2013;6:44.

24. Schunk M, Kumma WP, Miranda IB, Osman ME, Roewer S, Alano A, et al. High prevalence of drug-resistance mutations in Plasmodium falciparum and Plasmodium vivax in southern Ethiopia. Malar J. 2006;5:54.

25. Ketema T, Getahun K, Bacha K. Therapeutic efficacy of chloroquine for treatment of Plasmodium vivax malaria cases in Halaba district, South Ethiopia. Parasit Vectors. 2011:4:46.

26. The malERA Consultative Group on Vector Control. A research agenda for malaria eradication: vector control. PLoS Med. 2011:8:e1000401.

27. Mboera LEG, Kihonda J, Braks MAH, Knols BGJ. Short report: influence of centers for disease control light trap position, relative to a human-baited bed net, on catches of Anopheles gambiae and Culex quinquefasciatus in Tanzania. Am J Trop Med Hyg. 1998;59:595-6.

28. WHO. Malaria entomology and vector control. Guide for participants: training module on malaria control. Geneva: World Health Organization; 2011.

29. Silver JB. Mosquito ecology: field sampling methods. 3rd ed. Dordrecht: Springer; 2008

30. Gillies MT, Coetzee M. A supplement to the anophelinae of Africa south of the Sahara (Afrotropical Region). Johannesburg: South African Institute for Medical Research; 1987

31. Beier JC, Perkins PV, Wirtz RA, Koros J, Diggs D, Gargan TP, et al. Blood meal identification by direct enzyme-linked immunosorbent assay (ELISA) tested on Anopheles (Diptera: Culicidae) in Kenya. J Med Entomol. 1988:25:9-16.

32. Beier JC, Perkins PV, Wirtz RA, Whitmire RE, Mugambi M, Hockmeyer WT Field evaluation of an Enzyme-Linked Immunosorbent Assay (ELISA) for Plasmodium filciparum sporozoite detection in anopheline mosquitoes from Kenya. Am J Trop Med Hyg. 1987;36:459-68.

33. Muriu SM, Muturi EJ, Shililu Jl, Mbogo CM, Mwangangi JM, Jacob BG, et al Host choice and multiple blood feeding behaviour of malaria vectors and other anophelines in Mwea rice scheme, Kenya. Malar J. 2008;7:43.

34. Drakeley C, Schellenberg D, Kihonda J, Sousa CA, Arez AP, Lopes D, et al An estimation of the entomological inoculation rate for Ifakara: a semiurban area in a region of intense malaria transmission in Tanzania. Trop Med Int Health. 2003:8:767-74.

35. Beier JC. Vector incrimination and entomological inoculation rates. Methods Mol Med. 2002:72:3-11.

36. Kent RJ, Thuma PE, Mharakurwa S, Norris DE. Seasonality, blood feeding behavior, and transmission of Plasmodium falciparum by Anopheles arabiensis after an extended drought in southern Zambia. Am J Trop Med Hyg 2007:76:267-74.

37. Tekie H. The ecology of anthropophilic Anopheles mosquitoes in the Ghibe horticulture development farm. Addis Ababa: Addis Ababa University; 1989.

38. Animut A, Balkew M, Gebre-Michael T, Lindtjørn B. Blood meal sources and entomological inoculation rates of anophelines along a highland altitudinal transect in south-central Ethiopia. Malar J. 2013;12:76.

39. Gari T, Kenea O, Loha E, Deressa W, Hailu A, Balkew M, et al. Malaria incidence and entomological findings in an area targeted for a clusterrandomized controlled trial to prevent malaria in Ethiopia: results from a pilot study. Malar J. 2016;15:145

40. Kenea O, Balkew M, Tekie H, Gebre-Michael T, Deressa W, Loha E, et al. Human-biting activities of Anopheles species in south-central Ethiopia. Parasit Vectors. 2016:9:527.

41. Tirados I, Costantini C, Gibson G, Torr SJ. Blood-feeding behaviour of the malarial mosquito Anopheles arabiensis: implications for vector control. Med Vet Entomol. 2006:20:425-37. 
42. Tirados I, Gibson G, Young S, Torr SJ. Are herders protected by their herds? An experimental analysis of zooprophylaxis against the malaria vector Anopheles arabiensis. Malar J. 2011;10:68.

43. Mayagaya VS, Nkwengulila G, Lyimo IN, Kihonda J, Mtambala H, Ngonyani $\mathrm{H}$, et al. The impact of livestock on the abundance, resting behaviour and sporozoite rate of malaria vectors in southern Tanzania. Malar J. 2015;14:17.

44. Russell TL, Govella NJ, Azizi S, Drakeley CJ, Kachur SP, Killeen GF. Increased proportions of outdoor feeding among residual malaria vector populations following increased use of insecticide-treated nets in rural Tanzania. Malar J. 2011;10:80.

45. Moiroux N, Gomez MB, Pennetier C, Elanga E, Djènontin A, Chandre F, et al. Changes in Anopheles funestus biting behavior following universal coverage of long-lasting insecticidal nets in Benin. J Infect Dis. 2012;206:1622-9.

46. Mwangangi JM, Mbogo CM, Orindi BO, Muturi EJ, Midega JT, Nzovu $J$, et al. Shifts in malaria vector species composition and transmission dynamics along the Kenyan coast over the past 20 years. Malar J. 2013;12:13.

47. Ototo EN, Mbugi JP, Wanjala CL, Zhou G, Githeko AK, Yan G. Surveillance of malaria vector population density and biting behaviour in western Kenya. Malar J. 2015;14:244

48. Githeko AK, Service MW, Mbogo CM, Atieli FA, Juma FO. Sampling Anoph eles arabiensis, An. gambiae sensu lato and An. funestus (Diptera: Culicidae) with CDC light-traps near a rice irrigation area and a sugarcane belt in western Kenya. Bull Entomol Res. 1994;84:319-24.

49. Ogola E, Villinger J, Mabuka D, Omondi D, Orindi B, Mutunga J, et al. Composition of Anopheles mosquitoes, their blood-meal hosts, and Plasmodium falciparum infection rates in three islands with disparate bed net coverage in Lake Victoria, Kenya. Malar J. 2017;16:360.

50. Zhou G, Munga S, Minakawa N, Githeko AK, Yan G. Spatial relationship between adult malaria vector abundance and environmental factors in western Kenya highlands. Am J Trop Med Hyg. 2007;77:29-35.

51. Kirby MJ, Green C, Milligan PM, Sismanidis C, Jasseh M, Conway DJ, et al. Risk factors for house-entry by malaria vectors in a rural town and satellite villages in The Gambia. Malar J. 2008;7:2.

52. Mwangangi JM, Muturi EJ, Muriu SM, Nzovu J, Midega JT, et al. The role of Anopheles arabiensis and Anopheles coustani in indoor and outdoor malaria transmission in Taveta District. Kenya. Malar J. 2013;6:114.

53. Li L, Bian L, Yan G. A study of the distribution and abundance of the adult malaria vector in western Kenya highlands. Int J Health Geogr. 2008;7:50.
54. Staedke SG, Nottingham EW, Cox J, Kamya MR, Rosenthal PJ, Dorsey G. Short report: proximity to mosquito breeding sites as a risk factor for clinical malaria episodes in an urban cohort of Ugandan children. Am J Trop Med Hyg. 2003;69:244-6.

55. Peterson I, Borrell LN, El-Sadr W, Teklehaimanot A. Individual and household level factors associated with malaria incidence in a highland region of Ethiopia: a multilevel analysis. Am J Trop Med Hyg. 2009;80:103-11.

56. Hadis M, Lulu M, Makonnen Y, Asfaw T. Host choice by indoorresting Anopheles arabiensis in Ethiopia. Trans R Soc Trop Med Hyg. 1997;91:376-8

57. Massebo F, Balkew M, Gebre-Michael T, Lindtjørn B. Zoophagic behaviour of Anopheline mosquitoes in southwest Ethiopia: opportunity for malaria vector control. Parasit Vectors. 2015;8:645.

58. Bashar K, Tuno N, Ahmed TU, Howlader AJ. Blood-feeding patterns of Anopheles mosquitoes in a malaria-endemic area of Bangladesh. Parasit Vectors. 2012;5:39.

59. Ndenga BA, Mulaya NL, Musaki SK, Shiroko JN, Dongus S, Fillinger U. Malaria vectors and their blood-meal sources in an area of high bed net ownership in the western Kenya highlands. Malar J. 2016;15:76.

60. Bugoro H, Cooper RD, Butafa C, Iro'ofa C, Mackenzie DO, Chen C-C, et al. Bionomics of the malaria vector Anopheles farauti in Temotu Province, Solomon Islands: issues for malaria elimination. Malar J. 2011;10:133.

61. Habtewold T, Prior A, Torr SJ, Gibson G. Could insecticide-treated cattle reduce Afrotropical malaria transmission? Effects of deltamethrin-treated Zebu on Anopheles arabiensis behaviour and survival in Ethiopia. Med Vet Entomol. 2004;18:408-17.

62. Franco AO, Gomes MGM, Rowland M, Coleman PG, Davies CR. Controlling malaria using livestock-based interventions: a one health approach. PLoS One. 2014;9:e101699.

63. Degefa T, Zeynudin A, Godesso A, Haile Michael Y, Eba K, Zemene E, et al. Malaria incidence and assessment of entomological indices among resettled communities in Ethiopia: a longitudinal study. Malar J. 2015;14:24.

64. Churcher TS, Trape J-F, Cohuet A. Human-to-mosquito transmission efficiency increases as malaria is controlled. Nat Commun. 2015;6:6054.

\section{Publisher's Note}

Springer Nature remains neutral with regard to jurisdictional claims in published maps and institutional affiliations.
Ready to submit your research? Choose BMC and benefit from:

- fast, convenient online submission

- thorough peer review by experienced researchers in your field

- rapid publication on acceptance

- support for research data, including large and complex data types

- gold Open Access which fosters wider collaboration and increased citations

- maximum visibility for your research: over $100 \mathrm{M}$ website views per year

At BMC, research is always in progress.

Learn more biomedcentral.com/submissions 